\title{
Activation of ERK and Mutual Regulation of Stat3 and SP1 Contribute to Inhibition of PDK1 Expression by Atractylenolide-1 in Human Lung Cancer Cells
}

\author{
Qian Xiao $^{\mathrm{a}}$ Fang Zheng ${ }^{\mathrm{a}}$ JingJing Wu $\mathrm{Wu}^{\mathrm{a}}$ Qing Tang ${ }^{\mathrm{a}}$ Wei Wang ${ }^{\mathrm{b}}$ \\ Swei Sunny Hann ${ }^{a}$ \\ aLaboratory of Tumor Biology, ${ }^{b}$ Department of Gastrointestinal Surgery, Guangdong Provincial Hospital \\ of Chinese Medicine, The Second Clinical Medical Collage, Guangzhou University of Chinese Medicine, \\ Guangzhou, China
}

\section{Key Words}

Atractylenolide-1 $\bullet$ ERK1/2 $・$ Stat3 $・$ SP1 $・$ PDK1 $・$ Lung cancer cells

\begin{abstract}
Background/Aims: Atractylodes macrocephula Koidz is an important ingredient in traditional Chinese herbs. One major bioactive compound, atractylenolide-1 (ATL-1), was reported to have anti-inflammatory and anti-tumor activities. However, the underlying molecular mechanism associated to this has not been well elucidated. Methods: Cell viability and cell cycle distribution were measured using 3-(4, 5-dimethylthiazol-2-yl)-2, 5-diphenyltetrazolium bromide (MTT) and flow cytometry assays, respectively. Western blot analysis was performed to examine the phosphorylation and protein expression of extracellular signaling-regulated kinase 1/2 (ERK1/2), signal transducer and activator of transcription 3 (Stat3), 3-phosphoinositide dependent protein kinase-1 (PDK1) and transcription factor SP1. QRT-PCR was used to examine the mRNA levels of PDK1 gene. Exogenously expressions of Stat3, PDK1 and SP1 were carried out by transient transfection assays. PDK1 promoter activity was measured by Secrete-Pair Dual Luminescence Assay Kit. A nude mice xenograft model was used to confirm the findings in vitro. Results: We showed that ATL-1 inhibited human lung cancer cell growth and induced cell cycle arrest. Furthermore, we found that ATL-1 stimulated phosphorylation of ERK1/2, inhibited phosphorylation and protein expressions of Stat3 and SP1; the latter were abrogated in the presence of MEK/ERK inhibitor PD98059. Moreover, ATL-1 reduced the protein, mRNA expression and promoter activity of PDK1. Intriguingly, exogenously expressed Stat3 and SP1 overcame ATL-1-inhibited SP1 and Stat3, and PDK1 protein expressions, respectively. Moreover, overexpression of PDK1 resisted the ATL-1-inhibited lung cancer cell growth. In consistent with the results in vitro, ATL-1 inhibited tumor growth, protein expressions of Stat3, SP1 and PDK1, and induced phosphorylation of ERK1/2 in vivo. Conclusion: In summary, our


results show that ATL-1 inhibits lung cancer cell growth through activation of ERK1/2, followed by suppressing SP1 protein expression. ATL-1 also reduces phosphorylation and protein levels of Stat3. These are mutual regulation between Stat3 and SP1 proteins affected by ATL-1. This ultimately suppresses PDK1 gene expression. This study reveals a novel mechanism by which ATL-1 inhibits growth of lung cancer cells. Thus, targeting PDK1 pinpoints a potential in the lung cancer treatment.

(C) 2017 The Author(s)

Published by S. Karger AG, Basel

\section{Introduction}

Lung cancer including non-small cell lung cancer (NSCLC) is the most common and lethal malignancy worldwide. Despite improvements in diagnosis and combined treatments, the overall survival for NSCLC patients still remains unfavorable due to the toxicity and limited efficacy, thereby resulting in more than one-quarter of all lung cancer death [1]. The survival of advanced NSCLC still largely relied on systemic treatments [2]. The limited success rates in the treatment of advanced and metastatic NSCLC have presented challenges to current treatment paradigms. This has prompted the scientific world to search novel therapeutic modalities with more efficacy and minimal toxicity. Traditional Chinese Medicinal (TCM) compounds and its major components combined with chemotherapy appeared to be promising modalities for advanced NSCLC patients, resulting in reducing toxicity and increasing the quality of life, which potentially offered an attractive strategy for future adjunct treatment [3-6]. Among those, atractylodes macrocephula Koidz could be one such candidate.

Atractylodes macrocephula Koidz (A. macrocephula, also known as Baizhu), an important component in traditional Chinese herb medicine, have been shown to be beneficial for the treatment of variety of diseases including cancers by regulating various molecules and pathways [7-10]. Atractylenolide 1 (ATL-1), one of major bioactive compounds of Atractylodis macrocephalae, has anti-inflammatory and anti-tumor activities [8, 10-12]. For example, ATL-I induced cell cycle arrest and apoptosis via reduction of expression of cyclin B1 and cyclin dependent kinase 1 (CDK1), and inhibition of phosphatidylinositiol 3-kinaseAkt/mammalian target of rapamycin (PI3K/Akt/mTOR) pathway in ovarian cancer cells [13]. Also, ATL-1 has been shown to induce apoptosis in NSCLC A549 and HCC827 cells both in vitro and in vivo through mechanism involved in mitochondria-mediated apoptotic pathway [12]. Nevertheless, the detailed molecular mechanism underlying the effect of ATL1 in anti-lung cancer still remind unclear.

Signal-transducer-and-activator-of-transcription-3 (Stat3), a member of a family of six different transcription factors, has been implicated in various diseases and cancer. Deregulation of Stat3 promoted tumor growth through regulating the expression of genes involved in proliferation, apoptosis, and angiogenesis, among others [14, 15]. Several reports showed that inhibition of Stat 3 suppressed the growth of cancer cells and enhanced the sensitivity to anticancer agents in several cancer types [16-18]. Thus, targeting Stat3 has potential for prevention and treatment of cancers $[17,19]$. Stat 3 is persistently activated in NSCLC $[14,20]$, overexpression of Stat 3 resulted in poor prognosis, thus, high activation of p-Stat3 was considered as a diagnostic marker in patients with NSCLC [16]. However, the potential role of this molecule in mediating the effect of ATL-1 has not been recognized.

SP1 (specificity protein 1) is highly expressed in various cancers and identified as an oncogenic or tumor suppressor [21]. Regulation of SP1 has been implicated in variety of biological functions, such as cell growth, differentiation, apoptosis, angiogenesis and carcinogenesis through regulation of a number of oncogenes and tumor suppressors [21-23]. In most cases, high expression of SP1 is considered as a poor prognostic marker in patients with cancer $[24,25]$. And inhibition of SP1 signaling has been shown to be associated with suppressing lung cancer cell growth [26-28]. Thus, targeting SP1 may be beneficial in the treatment of cancer. At present, the connection between the SP1 signaling and ATL-1 has not been reported, thus, the potential role and function of SP1 in mediating 
the anti-cancer effects of ATL-1 remain to be determined. Moreover, the link of Stat 3 and SP1 signaling in regulation of physio-pathological functions including growth, differentiation and progression have been observed in several studies [29-31] implying important roles of the interaction in signal transduction and tumor growth.

3-phosphoinositide dependent protein kinase-1 (PDK1) is a master regulatory protein kinase and a member of the AGC protein kinase families. As a common upstream activator, PDK1 activates multiple downstream effectors, and has been implicated in development of various diseases and cancer [32]. Alteration of PDK1 is a critical component of oncogenic phosphoinositide 3-kinase (PI3-K) signaling in cancer, suggesting that inhibition of PDK1 can reduce tumor progression. Several pharmacological PDK1 inhibitors and knockdown of PDK1 inhibited tumor cell growth in vitro and attenuated the tumorigenesis, and growth in vivo in several tumor models [33-35]. Thus, PDK1 is a therapeutic target and modulating PDK1 pathway may represent a rational therapeutic strategy to prevent cancer progression and treatment [36-38]. The connections of Stat3 or/and SP1 in regulation of PDK1 expression have been shown in other studies [39-41], indicating that these molecules act cooperatively to regulate its downstream effectors and thereby promoting cancer progression.

In this study, we explored the potential molecular mechanism of the anti-lung-cancer effects of ATL-1.

\section{Materials and Methods}

\section{Reagents and cell cultures}

The antibodies against the total ERK1/2 and the phosphor-forms (Thr202/Tyr204), PD98059 were purchased from Cell Signaling Technology Inc. (Beverly, MA, USA). The phosphor-form (Tyr705) of Stat3, total Stat3, SP1 and PDK1 antibodies were obtained from Abcam (Cambridge, MA, USA). MTT agent was purchased from Sigma Aldrich (St. Louis, MO, USA). Lipofectamine 3000 reagent was obtained from Life Technologies (AB \& Invitrogen) (Carlsbad, CA, USA). ATL-1 was purchased from Chengdu Must Biotechnology Company (Chengdu, Sichuan, China). All other chemicals were purchased from Sigma Aldrich (St. Louis, MO, USA) unless otherwise indicated. NSCLC cells (A549 and H1299) obtained from the Chinese Academy of Sciences Cell Bank of Type Culture Collection (Shanghai, China) were cultured at $37^{\circ} \mathrm{C}$ in a humidified atmosphere containing 5\% CO2. The culture medium consisted of RPMI 1640 medium (Life Technologies, Carlsbad, CA, USA) supplemented with $10 \%(\mathrm{v} / \mathrm{v})$ heat-inactivated fetal bovine serum (Thermo Fisher Scientific Inc, Waltham, MA, USA), and $100 \mu \mathrm{g} / \mathrm{ml}$ streptomycin and $100 \mathrm{U} / \mathrm{mL}$ penicillin. In addition, Geneticin (G-418) sulfate (Life Technologies, Carlsbad, CA, USA) at concentration of $200 \mu \mathrm{g} / \mathrm{mL}$ was included in culturing A549-luc cells (obtained from the Guangzhou Land Technology Co., Guangzhou, China).

\section{Cell viability assay}

Cell viability was examined using the 3-(4, 5-dimethylthiazol-2-yl)-2, 5-diphenyltetrazolium bromide (MTT) assay as reported previously [42]. NSCLC cells $\left(2 \times 10^{4}\right.$ cells/well) seeded into 96-well plates were treated with increasing concentrations of ATL-1 for up to $72 \mathrm{~h}$. Afterwards, MTT solution (10 $\mu \mathrm{L}, 5 \mathrm{~g} / \mathrm{L})$ was added and incubated at $37^{\circ} \mathrm{C}$ for an additional $3 \mathrm{~h}$. After removing supernatant, solvent dimethyl sulfoxide $(150 \mu \mathrm{L})$ was added and oscillated for 5-10 min. Finally, optimal density was recorded at $490 \mathrm{~nm}$ absorbance using a spectrophotometer as per the manufacturer's instructions (Perkin Elmer, Victor X5, Waltham, MA, USA). The percentage of viable cells for the treatment group was calculated by adjusting the untreated control group.

\section{Cell cycle analysis}

This procedure was based on previous study [43]. Briefly, culturing A549 and H1299 cells $\left(1 \times 10^{5}\right.$ cells/6-well plates) were treated with increased concentrations of ATL-1 for up to $48 \mathrm{~h}$. Afterwards, the cells were incubated in $1 \mathrm{~mL}$ of $0.1 \%$ sodium citrate containing propidium iodide (PI) $0.05 \mathrm{mg}$ and $50 \mu \mathrm{g}$ RNase for $1 \mathrm{~h}$ at room temperature in dark conditions. Finally, the cells were then applied to FACScalibur flow cytometer (FC500, Beckman Coulter, FL, USA), and the proportion (percentage) of cells within the cell 


\section{Cellular Physiology Cell Physiol Biochem 2017;43:2353-2366

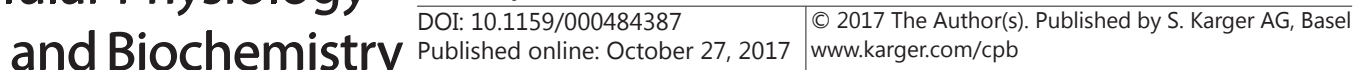 \\ Xiao et al.: Atractylenolide-1 Inhibits PDK1 Expression}

cycle were analyzed using the MultiCycle AV DNA Analysis software (Phoenix Flow Systems, Inc. San Diego, CA, USA).

\section{Quantitative real-time RT-PCR ( $q R T$-PCR)}

A quantitative real-time RT-PCR (qRT-PCR) assay was performed to examine PDK1 transcript. Total RNA was generated using RNA Easy Mini kit according to the instruction from manufacturer (Qiagen Inc, Valencia, CA, USA). The primers were as follows: PDK1 forward 5'--CAGAGGTCAGGCAGCAACAT-3 and reverse 5'-ACGTCCTGTTAGGCGTGTGG-3'; GAPDH forward 5'-AAGCCTGCCGGTGACTAAC-3'; reverse 5'-CGTCCTGTTAGGCAAGGGTT-3'. The first-strand cDNA was synthesized by reverse transcription using oligo-dT primers and Superscript II reverse transcriptase (Invitrogen, Grand Island, NY, USA) based on instructions from the manufacturer. The reaction mix contained $2 \mu \mathrm{L}$ of the cDNA preparation, $10 \mu \mathrm{L} 2 \mathrm{X}$ SYBR Green Premix ExTaq (Takara Bio Inc. Japan), $10 \mu \mathrm{M}$ primer in a final volume of $20 \mu \mathrm{L}$, and carried out on an ABI 7500 Real-Time PCR System (Applied Biosystems, Grand Island, NY, USA). The qRT-PCR was performed for 40 cycles with the following conditions: $30 \mathrm{~s}$ at $95^{\circ} \mathrm{C}$, followed by 40 cycles of $5 \mathrm{~s}$ at $95^{\circ} \mathrm{C}$, and $34 \mathrm{~s}$ at $60^{\circ} \mathrm{C}$. The average value in each sample triplicate was used to calculate the relative amount of PDK1 using $2^{-\Delta \Delta \mathrm{Ct}}$ methods.

\section{Western blot analysis}

The procedure was based on previous study [42]. In brief, equal amounts of protein from cell lysates were applied on SDS polyacrylamide gels. Membranes (Millipore, Billerica, MA, USA) were incubated separately with antibodies of phosphor-ERK1/2, total ERK1/2, phosphor-Stat3, Stat3, SP1, and PDK1 (1:1000). Afterwards, the membranes were incubated with a secondary antibody conjugated to horseradish peroxidase (1:3000, Cell Signaling, Beverly, MA, USA). Finally, the membranes were transferred to freshly made ECL solution (Immobilon Western; Millipore, Billerica, MA, USA) and immunoreactive bands were visualized using chemiluminescent reagent, and the quantitative analysis was determined with Image Lab software (Bio-Rad, Hercules, CA, USA).

\section{Transient transfection experiments}

The detailed procedure was reported before [44]. For each well, $2 \mu \mathrm{g}$ of the control and wild type pEZX-PG04-PDK1 promoter constructs (GeneCopoeia, Inc., Rockville, MD, USA) with or without $0.2 \mu \mathrm{g}$ of the internal control secreted alkaline phosphatase (SEAP) were co-transfected into the NSCLC cells $\left(2 \times 10^{5}\right.$ cells/well in 6-well dishes) with the Lipofectamine 3000 reagent. The measurement of luciferase activities was performed by the Secrete-Pair Dual Luminescence Assay Kit (GeneCopoeia, Inc.). In the separated experiment, NSCLC cells were transfected with either the control or the expression vectors of human PDK1, Stat3 and SP1 (final dose of $2 \mu \mathrm{g} / \mathrm{mL}$ ) obtained from OriGene Technologies, Inc. (Rockville, MD, USA) with the Lipofectamine 3000 reagent. Cells were treated with ATL-1 for the indicated time for all subsequent experiments.

\section{Anti-tumor efficacy studies in vivo}

Animal study was approved and performed according to the recommendations in the Guide for the Care and Use of Laboratory Animals in cancer research of Use Committee of Guangdong Provincial Hospital of Chinese Medicine. A total of 30 eight-week-old female nude mice were purchased from Guangdong Provincial Research Center for Laboratory Animal Medicine (Foshan, Guangdong, China) and maintained at the Animal Center of Guangdong Provincial Hospital of Chinese Medicine. A549-Luc cells $\left(1 \times 10^{6}\right.$ cells $)$ were given subcutaneously into mice and the xenografts were allowed to grow for 5 days when the initial measurement was available (1000-1500 $\left.\mathrm{mm}^{3}\right)$. The mice were randomly divided into three groups: control, low $(25 \mathrm{mg} / \mathrm{kg}$ ) and high doses (75 mg/kg) of ATL-1 groups, which were given daily intraperitoneal injection for up to 20 days ( $n=10$ /group) as reported in other study [45].

Mice were anesthetized by inhalation of $2 \%$ isoflurane and injected intraperitoneally with D-Luciferin (Caliper Life Sciences, Hopkinton, MA, USA), and bioluminescence imaging (BLI) were performed for evaluation of tumor growth using IVIS-200 Imaging System (Caliper Life Sciences, Alameda, CA, USA). A formula for an oblong sphere: volume $=\left(\right.$ width $^{2} \times$ length $)$ were used for examining the tumor size. Quantification of bioluminescence was expressed as photons/sec. The body weights of the mice were documented once a week and all mice were euthanized on day 20 by cervical dislocation with minimum 
suffering. Tumors were excised and weighed, and processed for protein measurement of phosphorERK1/2, Stat3, SP1, and PDK1.

\section{Statistical analysis}

All data were expressed as mean \pm SD of three separated experiments. The statistically significant differences $(\mathrm{P}<0.05)$ were examined by student's t-test and ANOVA by Microsoft Excel 2016 (Microsoft, Washington, USA) and GraphPad Prism 5.03 software (La Jolla, CA, USA).

\section{Results}

ATL-1 inhibited growth and induced cell cycle arrest in human lung cancer cells.

We started to examine the effect of ATL-1 on growth in human NSCLC cells using MTT assay. We observed that ATL-1 decreased the cell growth in a dose- -dependent fashion with significant effect starting at 50 until $150 \mu \mathrm{M}$ for up to $72 \mathrm{~h}$ in A549 and H1299 NSCLC cells (Fig. 1A). The IC50 from 24 to $72 \mathrm{~h}$ were 149, 143, 110 and 107, 102, $83 \mu \mathrm{M}$ in A549 and H1299 cells, respectively. Moreover, the cell cycle distribution treated with increased doses of ATL-1 for $48 \mathrm{~h}$ was analyzed by flow cytometry. We found that, compared with the untreated control cells, ATL-1 significantly increased the proportion of cells at G0/G1 phases, while the proportion of cells at S phase was reduced in A549 and H1299 cells, respectively (Fig. 1B-C). Together, these findings suggested that ATL-1 inhibited cell growth and induced cell cycle arrest at G0/G1 phases in NSCLC cells.

Fig. 1. ATL-1 inhibited growth and induced cell cycle arrest in human lung cancer cells. A, A549 and H1299 cells were treated with increased concentrations of ATL-1 for up to 72 h. Afterwards, the cell growth was determined using the MTT assay as described in the Materials and Methods section. B-C, A549 and H1299 cells were treated with indicated concentrations of ATL-1 for $24 \mathrm{~h}$. The cells were collected and processed for analysis of cell cycle distribution. Cell cycle was analyzed by flow cytometry after

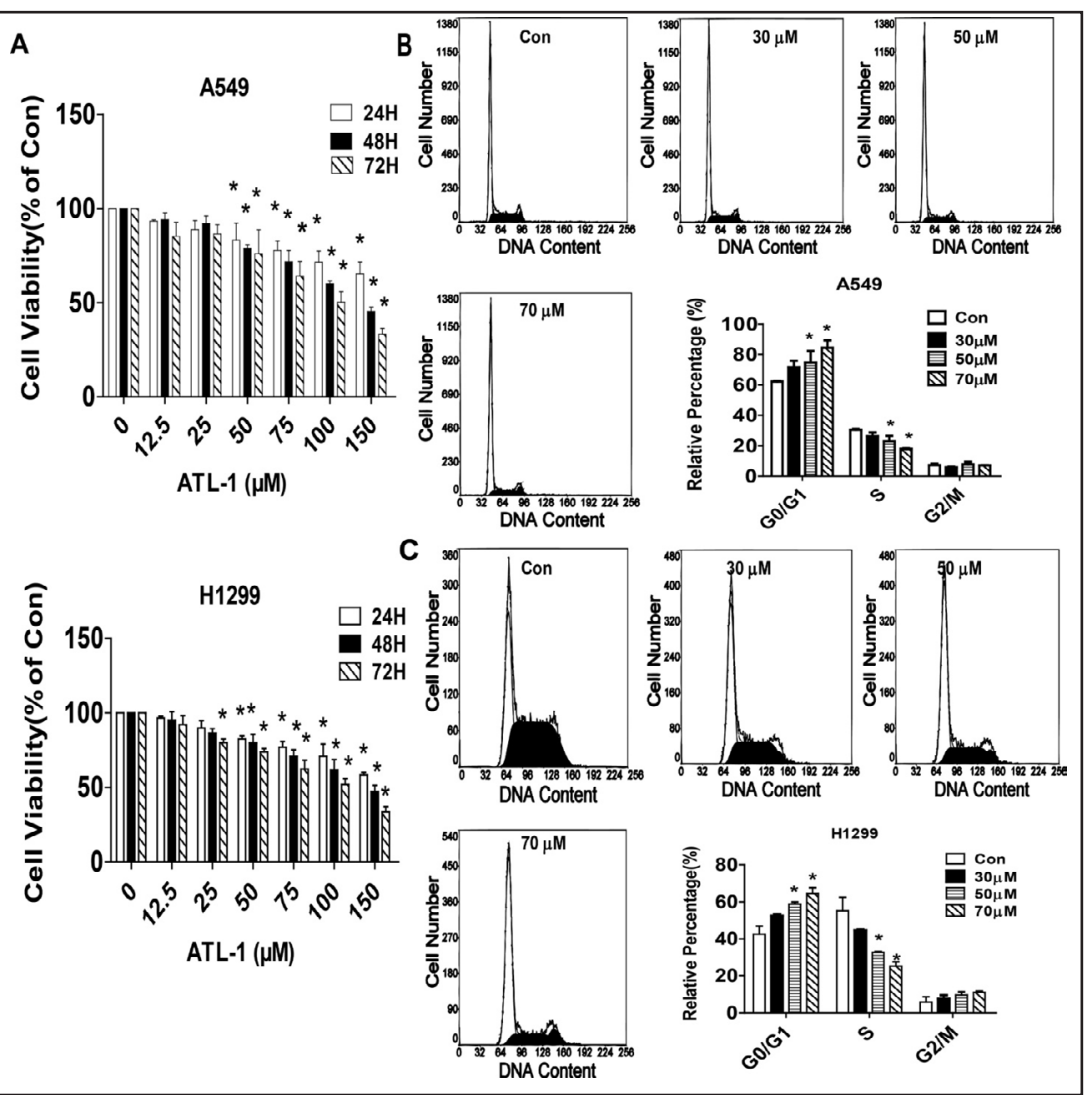
propidium iodide

(PI) staining, and the percentages of the cell population in each phase (G0/G1, S and G2/M) of cell cycle were analyzed by Multicycle AV DNA Analysis Software. Data are expressed as a percentage of total cells. Values are given as the mean \pm SD from 3 independent experiments. *Indicates $\mathrm{P}<0.05$ versus control group $(\mathrm{P}<0.05)$. 
Fig. 2. ATL-1 stimulated the phosphorylation of ERK1/2 in time-dependent manner. A-B, A549 (A) and H1299 (B) cells were treated with ATL-1 $(70 \mu \mathrm{M})$ in the indicated times, and cell lysate was harvested and the expression of the phosphorylated or total protein of ERK1/2 were measured by Western blot analysis using corresponding antibodies. GAPDH was used as loading control. Figures are representative cropped gels/blots that have been run under the same experimental conditions. The bar graphs represented the densitometry results of p-ERK1/2/ERK1/2 as mean \pm SD of at least three separate experiments. *Indicates significant difference from untreated control cells $(\mathrm{P}<0.05)$.
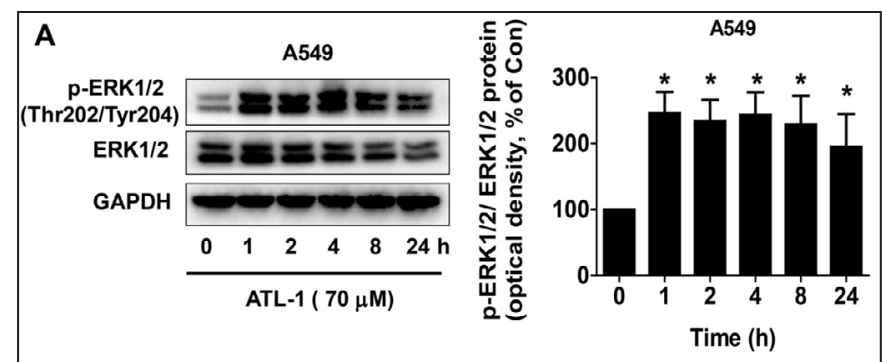

B
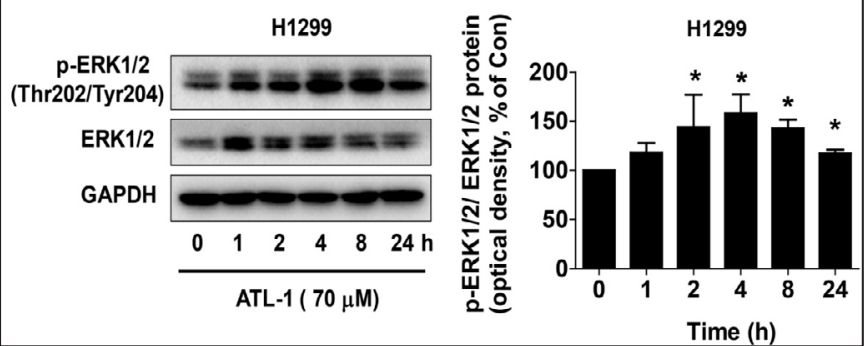

Fig. 3. ATL1 inhibited the protein expression of Stat3 and SP1 through activation of ERK1/2. A-B, A549 and H1299 cells were exposed to increased concentrations of ATL1 for $24 \mathrm{~h}$, follow ed by measuring p-Stat3, Stat3 and SP1 proteins by $\mathrm{W}$ e s t e r $\mathrm{n}$ blot. C-D, A549 and H1299 cells were treated

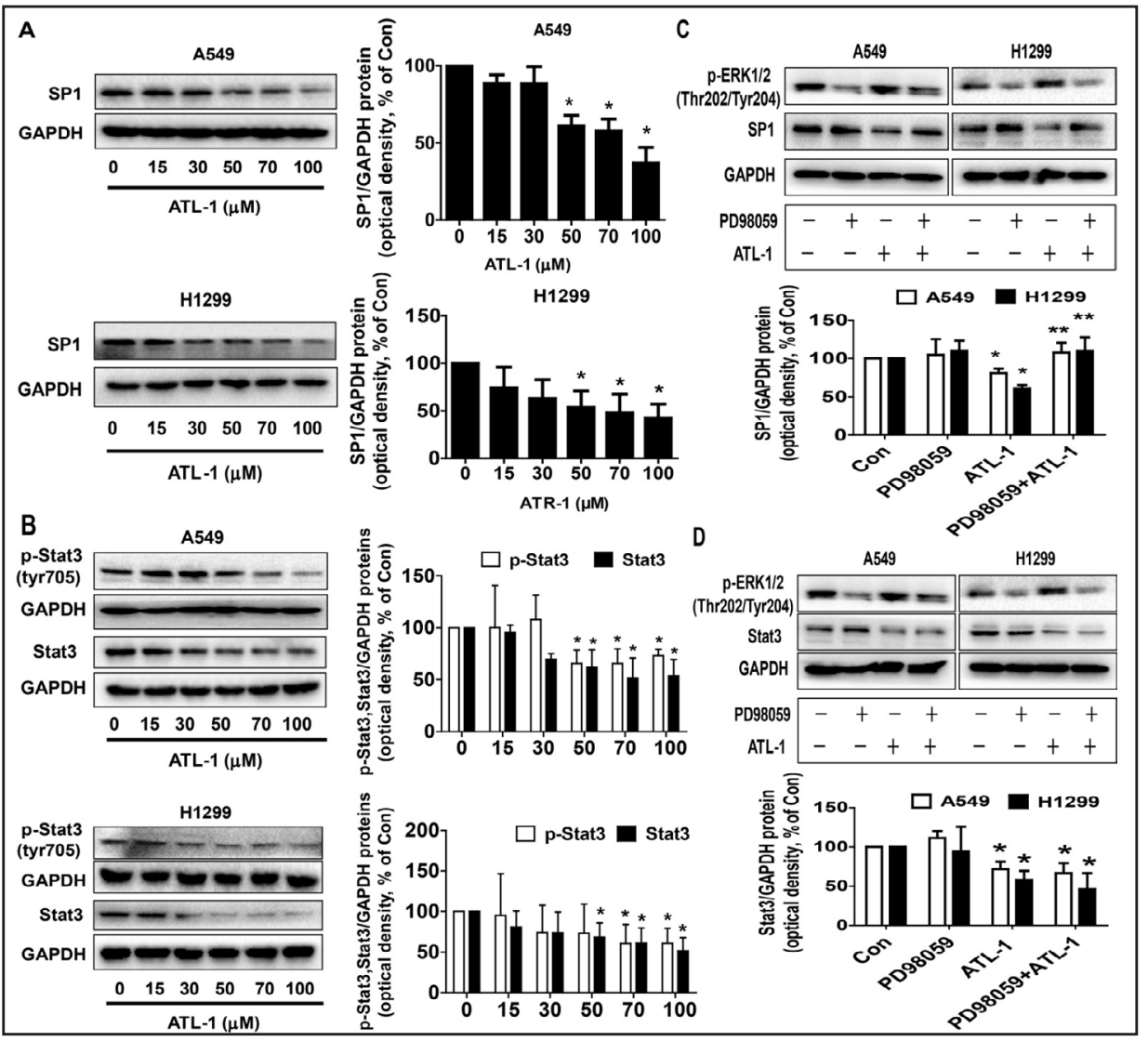
with PD98059 $(20 \mu \mathrm{M})$ for $2 \mathrm{~h}$ before exposure the cells to ATL-1 $(70 \mu \mathrm{M})$ for up to $24 \mathrm{~h}$. Afterwards, pERK1/2, Stat3 and SP1 protein expressions were determined using Western blot. GAPDH was used as loading control. Figures are representative cropped gels/blots that have been run under the same experimental conditions. Values in bar graphs were given as the mean \pm SD from three independent experiments performed in triplicate. ${ }^{*}$ Indicates significant difference as compared to the untreated control group $(\mathrm{P}<0.05)$. **Indicates significant difference from ATL-1 treated alone $(\mathrm{P}<0.05)$. 


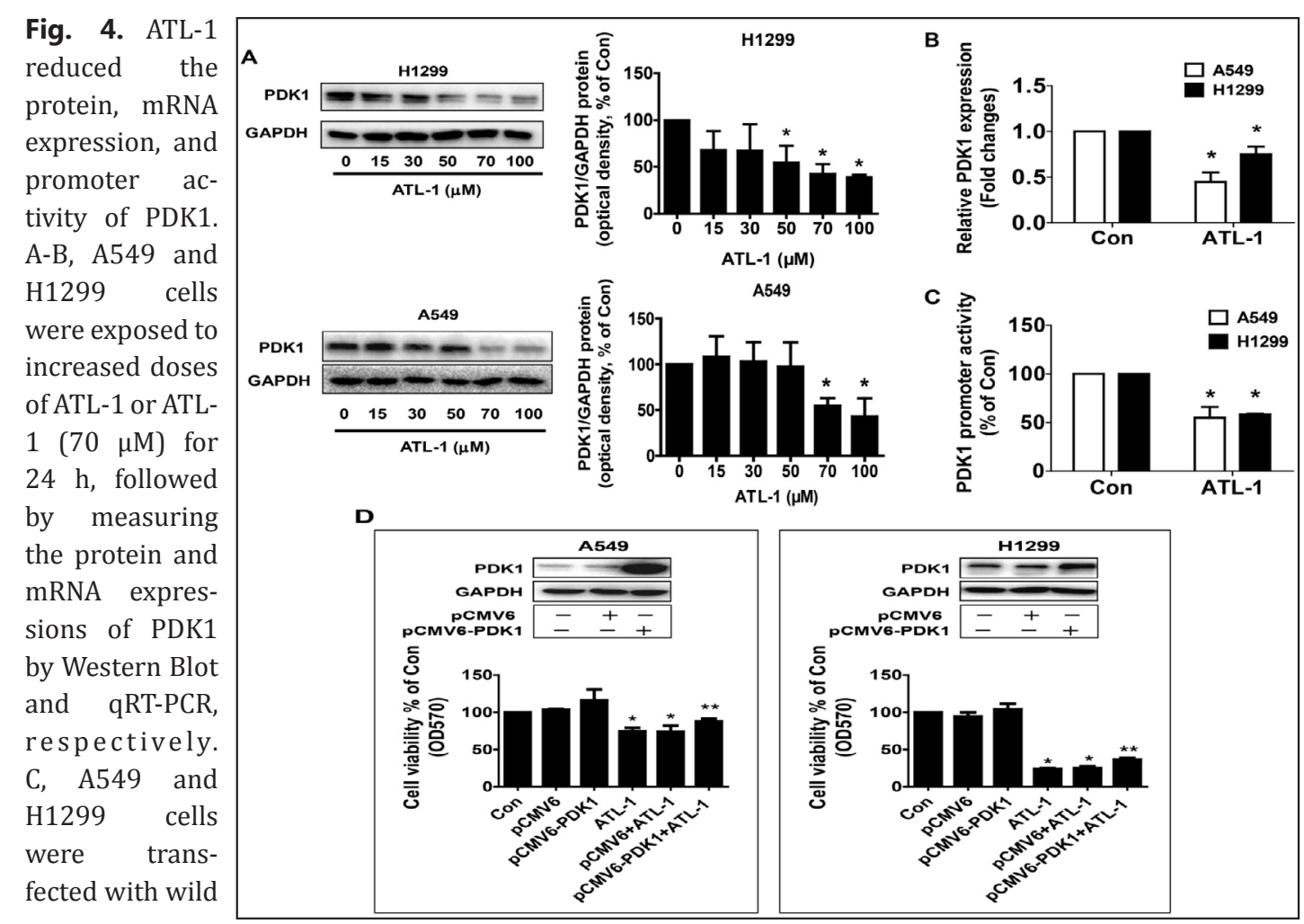

type human PDK1 promoter reporter construct ligated to luciferase reporter gene and internal control secreted alkaline phosphatase for $24 \mathrm{~h}$, followed by treating with ATL-1 for an additional $24 \mathrm{~h}$. Afterwards, the promoter activities were determined using the Secrete-Pair Dual Luminescence Assay Kit as described in the Materials and Methods section. D, A549 and H1299 cells were transfected with the control or expression constructs of PDK1 for $24 \mathrm{~h}$ before exposing the cells to ATL-1 (70 $\mu \mathrm{M})$ for an additional $48 \mathrm{~h}$. Afterwards, the cell viability was determined using the MTT assay as described in the Materials and Methods section. Insert on the upper panel represented the protein levels of PDK1 as determined by Western blot. GAPDH was used as internal control. *Indicates significant difference as compared to the untreated control group $(\mathrm{P}<0.05)$. **Indicates significant difference from ATL-1 treated alone $(\mathrm{P}<0.05)$.

\section{ATL-1 induced the phosphorylation of ERK1/2.}

Because of the possible dual roles of ERK1/2 signaling in pro- or anti-tumorigenic processes [46], we then assessed the effect of ATL-1 on regulation of ERK signaling in this process. We found that ATL-1 induced the phosphorylation of ERK1/2 with substantial activation noticed at 1-24 h and 4-24 h in A549 and H1299 cells, respectively (Fig. 2A-B). Note that shorter exposure (less than $1 \mathrm{~h}$ ) had little effects (not shown).

ATL-1 reduced the protein expressions of Stat3 and SP1 through activation of ERK1/2.

Transcription factors Stat3 and SP1 have been shown to be involved in the tumor growth and progression [47]. Because of this, we next attempted to test the effect of ATL-1 on Stat3 and SP1 signaling, respectively. We observed that ATL-1 reduced the protein levels of SP1 with significant effect found at $50 \mu \mathrm{M}$ for $24 \mathrm{~h}$ in A549 and H1299 cells (Fig. 3A). As expected, the similar findings were also observed in reduction of Stat3 protein expression in A549 and H1299 cells (Fig. 3B). Note that ATL-1 also inhibited phosphorylation of Stat3 (Tyr705) at dose-dependent manner (Fig. 3B). We then characterized the role of ERK1/2 involving in the effect of ATL-1 on protein expressions of Stat 3 and SP1. Interestingly, the specific inhibitor of MEK/ERK (PD98059) antagonized the ATL-1-inhibited expression of SP1 protein (Fig. 3C). However, no changes were observed in the presence or absence of PD98059 for Stat 3 protein levels (Fig. 3D). These findings suggested that activation of MEK/ERK may be involved in the inhibitory response of ATL-1 on SP1 protein expression in this process. 


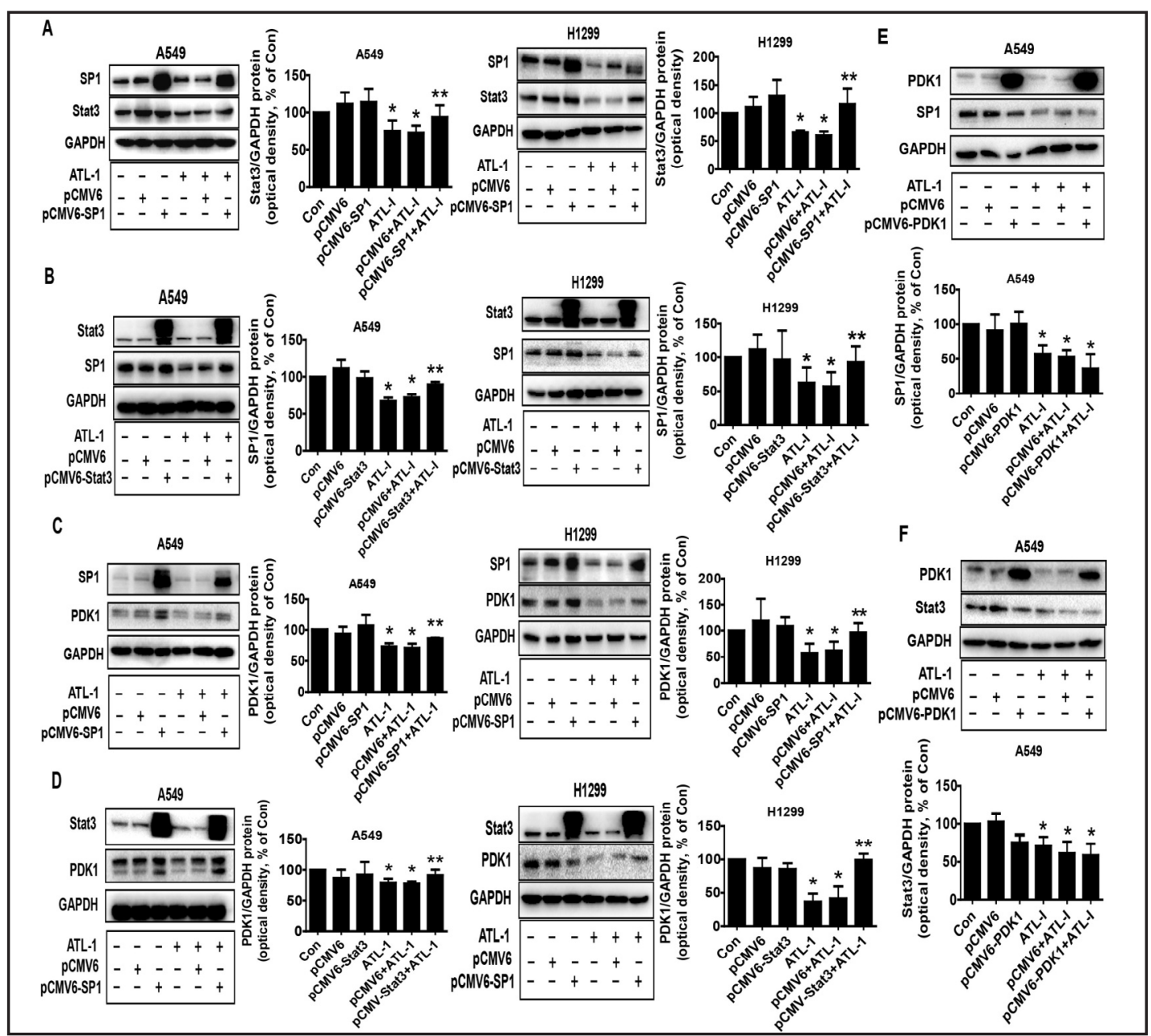

Fig. 5. Exogenously expressed SP1 and Stat 3 overcame the ATL-1-inhibited Stat3 and SP1, and PDK1 protein expressions, respectively. A, A549 and H1299 cells were transfected with the control or expression constructs of SP1 for $24 \mathrm{~h}$ before exposing the cells to ATL-1 for an additional $24 \mathrm{~h}$. Afterwards, SP1 and Stat3 protein expressions were determined by Western blot. B, A549 and H1299 cells were transfected with the control or expression constructs of Stat3 for $24 \mathrm{~h}$ before exposing the cells to ATL-1 for an additional 24 h. Afterwards, Stat3 and SP1 protein expressions were determined by Western blot. C-D, A549 and H1299 cells were transfected with the control or expression constructs of SP1 (C) Stat3 (D) for $24 \mathrm{~h}$ before exposing the cells to ATL-1 for an additional $24 \mathrm{~h}$. Afterwards, Stat3 or SP1 and PDK1 protein expressions were determined using Western blot. E-F, A549 cells were transfected with the control or expression constructs of PDK1 for $24 \mathrm{~h}$ before exposing the cells to ATL-1 for an additional $24 \mathrm{~h}$. Afterwards, Stat3, SP1 and PDK1 protein expressions were determined using Western blot. GAPDH was used as loading control. Figures are representative cropped gels/blots that have been run under the same experimental conditions. *Indicates significant difference as compared to the untreated control group $(\mathrm{P}<0.05) .{ }^{* *}$ Indicates significant difference from ATL-1 treated alone $(\mathrm{P}<0.05)$.

ATL-1 inhibited the expressions of protein, $m$ RNA levels, and promoter activity of PDK1.

As a master regulatory protein kinase of multiple downstream effectors, PDK1 has often been implicated in various diseases and particularly contributed to tumor cell growth, invasion and metastasis [32]. To further clarify the mechanism underlying the anti-lung cancer effect of ATL-1, we decipher the role of PDK1 in this process. We showed that ATL1 reduced protein and mRNA levels of PDK1 as determined by Western Blot and qRT-PCR (Fig. 4A-B). In addition, we observed that ATL-1 decreased promoter activity of PDK1 gene 


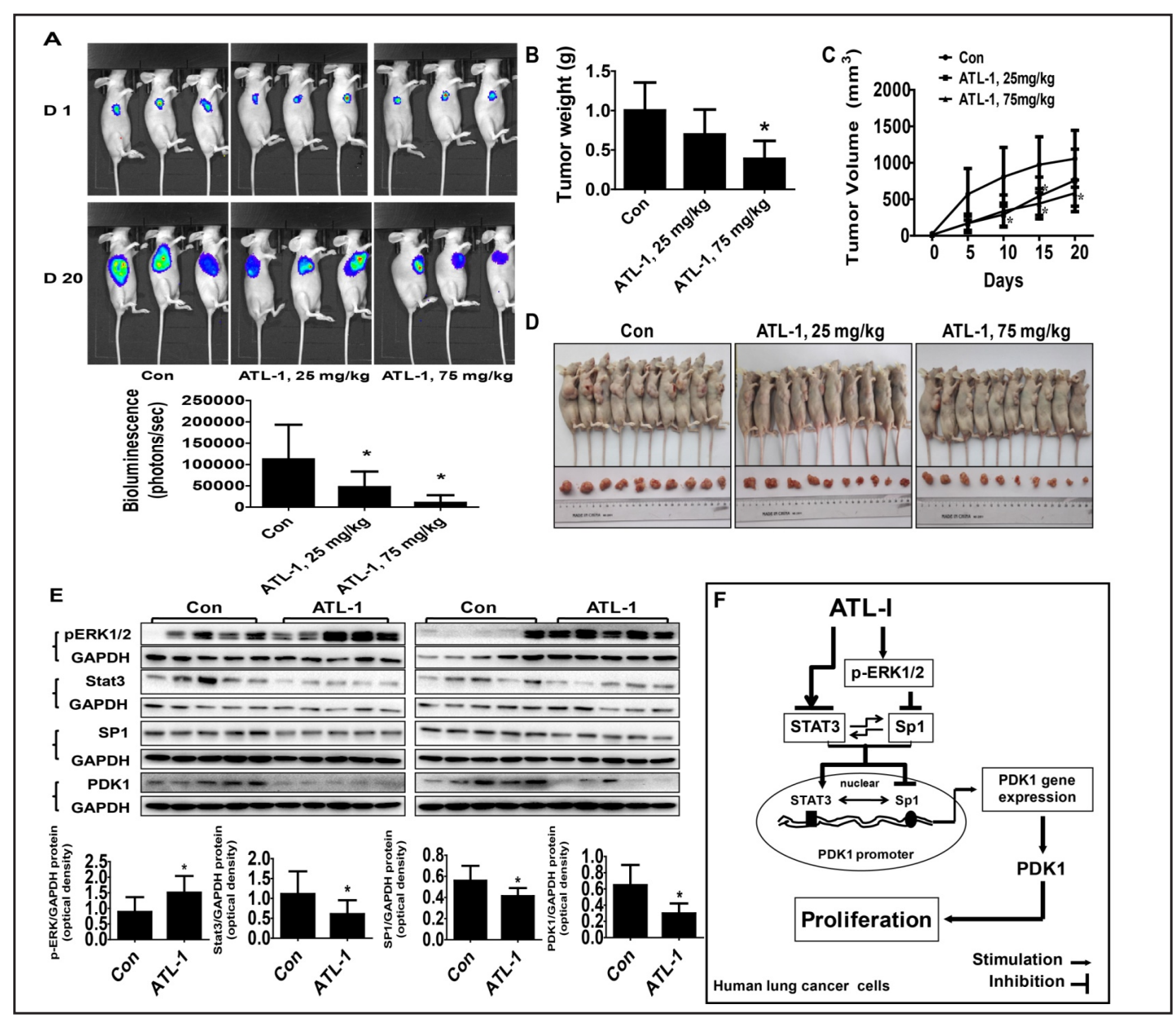

Fig. 6. Anti-tumor effects of ATL-1 in vivo. Mice ( $\mathrm{n}=10 /$ group) were divided to 3 groups [Con (saline), Low (L, $25 \mathrm{mg} / \mathrm{kg}$ ) and High (H, $75 \mathrm{mg} / \mathrm{kg}$ ) doses], and ATL-1 was given intraperitoneally daily around the $5^{\text {th }}$ day after tumor cells injection for up to 20 days. A, The xenografts were assessed by in vivo bioluminescence imaging at the end of the experiments (on day 20). The tumor growth was monitored by injecting luciferin in the mice followed by measuring bioluminescence using IVIS Imaging System. Imaging and quantification of signals were controlled by the acquisition and analysis software living image as described in the Materials and Methods section. Representative images are shown. B-C, The xenografts were harvested on day 20 , and the volume and weight of tumors were measured. The bar graphs represented the tumor weight and volume of mice results of as mean \pm SD from three independent experiments. D, The photographs of ATL-1 or vehicle-treated xenografts derived from nude mice are shown. E, At the end of the experiments, xenografted tumors were isolated from individual animals and the corresponding lysates were processed for detecting Stat3, SP1, PDK1 and p-ERK1/2 by Western blot. GAPDH was used as loading control. Values in bar graphs were given as the mean \pm SD from three independent experiments *Indicates the significant difference from untreated control $(\mathrm{p}<0.05)$. F, The diagram shows that ATL-1 inhibits lung cancer cell growth through activation of ERK1/2, followed by suppressing SP1 protein expression. ATL-1 also reduces phosphorylation and protein levels of Stat3. These are mutual regulations between Stat3 and SP1 proteins affected by ATL-1, which ultimately suppress PDK1 gene expression.

in A549 and H1299 cells (Fig. 4C). To further encircle and explore the regulatory function of PDK1 played in this process, we detected the role of PDK1 in mediating the effect of ATL-1 on cell growth inhibition. For this, we transfected the exogenously expressed PDK1 plasmid into the cells and observed that overexpression of PDK1 overcame the ATL-1-inhibited growth in A549 and H1299 cells (Fig. 4D). The results suggested a critical role of PDK1 in mediating the ATL-1-inhibited growth of NSCLC cells.

\section{KARGER}




\section{Cellular Physiology Cell Physiol Biochem 2017;43:2353-2366

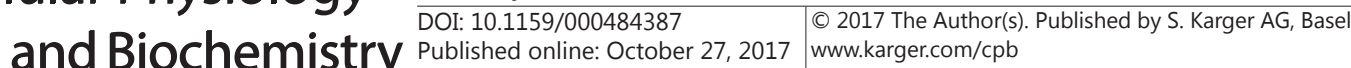 \\ Published online: October 27,2017 wide-1 Inhibits PDK1 Expression}

Exogenously expressed SP1 and Stat3 overcame the ATL-1-inhibited Stat3 and SP1, and PDK1 protein expressions, respectively.

In order to define the causational relations among Stat3, SP1, and PDK1, and determine the precise function of these factors that mediated the effect of ATL-1 in this process, we then transfected with expression vectors of SP1 and Stat3 into the cells, respectively. Our results showed that overexpressed SP1 reversed the effect of ATL-1 in inhibition of Stat3 protein, whereas exogenously expressed Stat 3 also reversed effect of ATL-1 on SP1 protein expression in A549 and H1299 cells (Fig. 5A-B). This suggested that there was a mutual regulation between the Stat 3 and SP1 affected by ATL-1 in this process. Interestingly, overexpressed Stat3 and SP1 showed to overcome the effect of ATL-1 on PDK1 protein expression in A549 and H1299 cells (Fig. 5C-D). On the contrary, overexpressed PDK1 had no effect on either SP1 or Stat3 in A549 cells (Fig. 5E-F). Together, the above findings indicated that there was a causational relation among Stat3 and SP1, and PDK1, and that the mutual regulation of Stat3 and SP1 converge on the inhibition of PDK1 expression affected by ATL-1.

\section{Anti-tumor effects of ATL-1 in vivo}

To further validate our findings in vitro, the effect of ATL-1 on tumor growth and expression of PDK1 in xenografted nude mouse model were also examined. Mice bearing xenografted tumor was given by intraperitoneal different doses of ATL- 1 daily ( 25 and 75 $\mathrm{mg} / \mathrm{kg}$, respectively) [45] for up to 20 days. We found that the high dose ATL-1-treated mice showed a significant delayed tumor growth without any severe adverse events as compared to that in the control group (Fig. 6A). Also, substantial reductions of the tumor weight and volume were observed in the high doses of ATL-1 treatment group as compared to that in the control one (Fig. 6B-D). In addition, fresh tumors harvested from the above experiments showed that ATL-1 efficiently decreased phosphorylation of ERK1/2, protein expressions of Stat3, SP1, and PDK1 in vivo in the high dose ATL-1 treatment group as compared to that in the control one by Western blot (Fig. 6E).

\section{Discussion}

Natural products are a large reservoir for anti-cancer drug discovery due to their enormous structural diversity and biological functions. Atractylenolide 1 (ATL-1), ATL2 , and ATL-3 are the major bioactive components of medicinal herb Rhizoma Atractylodis Macrocephalae (Atractylodes macrocephala) and demonstrate anti-inflammatory and anticancer activities. However, the in-depth molecular mechanism underlying the anticancer effects of the major active compound, ATL-1, still remained unclear [8, 45, 48]. In the present study, we provided evidence demonstrating the anti-lung cancer effects of ATL-l. The doses of ATL-1 in the current study were similar or even lower than those reported by others demonstrating substantial anti-cancer responses in several cancer types [13, $45,49]$. Our results showed that ATL- 1 inhibited lung cancer cell growth through ERK1/2mediated suppression of Stat 3 and SP1 protein expressions. This in turn reduced PDK1 gene expression. Moreover, the inter-correlation between Stat3 and SP1 may also corroborate to the overall effects of ATL- 1 in this process.

Mechanistically, we demonstrated the involvement of ERK signaling in mediating the anti-lung cancer cell growth inhibition. Activation of ERK1/2 was involved in the anti-tumor resposnes in several other studies in different cancer types including lung [50,51] although opposite reports have also been reported [52-54]. Thus, the possible dual roles of ERK signaling in terms of tumor suppressor or tumor promoter have been considered depending upon the reagents used, activity of ERK signaling, feedback loops, interaction with other kinase, and cell types studied [46]. Our results suggested that activation of ERK1/2 was involved in the inhibitory responses of ATL-1 in lung cancer cells.

Moreover, we observed the critical roles of Stat3 and SP1 involved in the inhibitory effect of ATL-1 in lung cancer cells. Acted as tumor promoters and oncogenes, Stat 3 and SP1 regulated a number of functions critical to growth, progression, apoptosis, and metastasis; 
thus, inhibition Stat3 signaling and SP1 expression have been reported to be involved in controlling cancer survival through different molecular mechanisms [55, 56]. Moreover, in further characterizing the potential links of these two molecules, we observed a mutual regulation between Stat 3 and SP1 affected by ATL-1 in our current study. The link of Stat3 and SP1 signaling in regulating cellular functions including tumor progression, apoptosis, angiogenesis, metastasis, and other gene expression were reported in other studies [30, $55,57]$ indicating the crosstalk of SP1 and Stat3 in tumor signal transduction. One recent report showed that a crosstalk of Stat 3 and SP1 functionally regulated several associated downstream genes and stimulated pancreatic cancer growth [56]. Thus, these factors work cooperatively to regulate its downstream effectors and promote cancer growth, and modulation of SP1 and Stat3 could be potential in prevention and treatment of cancer. Of note, ATL-1 also reduced phosphorylation of Stat3 implying that both inactivation and expression of Stat3 played role in this process.

More importantly, we identified an important role of PDK1 in this process. Our findings have indicated that reduction of PDK1 gene expression by ATL-1 is involved in inhibition of lung cancer cell growth. This strengthens the notion that PDK1 is an important target in developing novel anti-cancer strategies. Inhibition of PDK1 expression has been shown to be involved in the control of tumor cell growth and progression in several cancer types [36, 58$60]$ suggesting a critical role of this molecule. We also demonstrated that the interaction and correlation between Stat3 and SP1 regulated the expression of PDK1 in this process, thus inhibition of these two factors was strongly associated with the reduction of PDK1 expression by ATL-1. The links of Stat3 or/and SP1 signaling in regulation of PDK1 expression have also been reported in other studies [39-41]. PDK1 is known target gene of Stat3 and activation of Stat3 associates with hypoxia inducible factor mediated gene expression including PDK1 in several cancer cells [39]. PDK1 promoter region contained SP1 binding sites, and factors, such as c-Jun, could influence the expression of PDK1 through cooperation with SP1 and others in the corresponding response elements in PDK1 promoter in melanoma cells [41]. Overall, these observations highlighted the links and interactions among these molecules in regulation of biological functions and cancer progression.

Moreover, our in vivo results fit the observation in vitro, further confirming the inhibitory effect of ATL-1 on lung tumor growth, and regulation of Stat3, SP1, and PDK1 expressions. The doses of ATL-1 used were based on other study, which showed significant inhibitory effects on tumor growth without noticeable toxicity [45]. We believed that more studies are needed to further determine the important role of PDK1 in this process using cells stable transfected with shRNAs and overexpression of PDK1 gene in animal models.

Collectively, our results show that ATL-1 inhibits lung cancer cell growth through activation of ERK1/2, followed by suppressing SP1 protein expression. ATL-1 also reduces phosphorylation and protein levels of Stat3. This is a mutual regulation between Stat3 and SP1 proteins affected by ATL-1. This ultimately suppresses PDK1 gene expression (Fig. 6F). This study reveals a novel mechanism by which ATL-1 inhibits growth of lung cancer cells and further confirms that targeting PDK1 pinpoints a potential in the lung cancer treatment.

\section{Acknowledgements}

This work was supported in part by the grants from the National Nature Scientific Foundation of China $(81272614,81403216,81703551)$, the Science and Technology Program of Guangzhou (201607010385), the Discipline of Integrated Chinese and Western Medicine in Guangzhou University of Chinese Medicine (A1-Af-D018161Z1513), the Special Science and Technology Join fund from Guangdong Provincial Department of Science and Technology-Guangdong Academy of Traditional Chinese Medicine (2014A020221024), and the Specific Research Fund for TCM Science and Technology of Guangdong Provincial Hospital of Chinese Medicine (YK2013B2N13, YN2015MS19). 


\section{Cellular Physiology Cell Physiol Biochem 2017;43:2353-2366

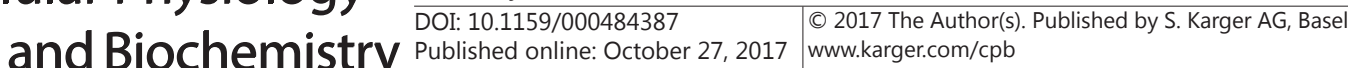 \\ Xiao et al.: Atractylenolide-1 Inhibits PDK1 Expression}

\section{Disclosure Statement}

The authors declare that they have no competing interests.

\section{References}

1 Siegel RL, Miller KD, Jemal A: Cancer statistics, 2016. CA Cancer J Clin 2016;66:7-30.

-2 Tomasini P, Barlesi F, Mascaux C, Greillier L: Pemetrexed for advanced stage nonsquamous non-small cell lung cancer: Latest evidence about its extended use and outcomes. Ther Adv Med Oncol 2016;8:198-208.

-3 Ye YT, Zhong W, Sun P, Wang D, Wang C, Hu LM, Qian JQ: Apoptosis induced by the methanol extract of salvia miltiorrhiza bunge in non-small cell lung cancer through pten-mediated inhibition of pi3k/akt pathway. J Ethnopharmacol 2017;200:107-116.

-4 Liu ZL, Zhu WR, Zhou WC, Ying HF, Zheng L, Guo YB, Chen JX, Shen XH: Traditional chinese medicinal herbs combined with epidermal growth factor receptor tyrosine kinase inhibitor for advanced non-small cell lung cancer: A systematic review and meta-analysis. J Integr Med 2014;12:346-358.

5 Zhou ZY, Xu L, Li HG, Tian JH, Jiao LJ, You SF, Han ZF, Jiang Y, Guo HR, Liu H: Chemotherapy in conjunction with traditional chinese medicine for survival of elderly patients with advanced non-small-cell lung cancer: Protocol for a randomized double-blind controlled trial. J Integr Med 2014;12:175-181.

6 Jiang Y, Liu LS, Shen LP, Han ZF, Jian H, Liu JX, Xu L, Li HG, Tian JH, Mao ZJ: Traditional chinese medicine treatment as maintenance therapy in advanced non-small-cell lung cancer: A randomized controlled trial. Complement Ther Med 2016;24:55-62.

7 Wang A, Xiao Z, Zhou L, Zhang J, Li X, He Q: The protective effect of atractylenolide i on systemic inflammation in the mouse model of sepsis created by cecal ligation and puncture. Pharm Biol 2016;54:146-150.

-8 Huang HL, Lin TW, Huang YL, Huang RL: Induction of apoptosis and differentiation by atractylenolide-1 isolated from atractylodes macrocephala in human leukemia cells. Bioorg Med Chem Lett 2016;26:19051909.

-9 Song HP, Li RL, Zhou C, Cai X, Huang HY: Atractylodes macrocephala koidz stimulates intestinal epithelial cell migration through a polyamine dependent mechanism. J Ethnopharmacol 2015;159:23-35.

10 Li W, Zhi W, Liu F, He Z, Wang X, Niu X: Atractylenolide i restores ho-1 expression and inhibits ox-ldlinduced vsmcs proliferation, migration and inflammatory responses in vitro. Exp Cell Res 2017;353:26-34.

$>11$ Ji G, Chen R, Zheng J: Atractylenolide i inhibits lipopolysaccharide-induced inflammatory responses via mitogen-activated protein kinase pathways in raw264.7 cells. Immunopharmacol Immunotoxicol 2014;36:420-425.

12 Liu H, Zhu Y, Zhang T, Zhao Z, Zhao Y, Cheng P, Li H, Gao H, Su X: Anti-tumor effects of atractylenolide i isolated from atractylodes macrocephala in human lung carcinoma cell lines. Molecules 2013;18:1335713368.

13 Long F, Wang T, Jia P, Wang H, Qing Y, Xiong T, He M, Wang X: Anti-tumor effects of atractylenolide-i on human ovarian cancer cells. Med Sci Monit 2017;23:571-579.

14 Peyser ND, Grandis JR: Critical analysis of the potential for targeting stat3 in human malignancy. Onco Targets Ther 2013;6:999-1010.

15 Hu W, Jin P, Liu W: Periostin contributes to cisplatin resistance in human non-small cell lung cancer a549 cells via activation of stat3 and akt and upregulation of survivin. Cell Physiol Biochem 2016;38:1199-1208.

16 Harada D, Takigawa N, Kiura K: The role of stat3 in non-small cell lung cancer. Cancers (Basel) 2014;6:708722.

17 Zhou Y, Tang Q, Zhao S, Zhang F, Li L, Wu W, Wang Z, Hann S: Targeting signal transducer and activator of transcription 3 contributes to the solamargine-inhibited growth and -induced apoptosis of human lung cancer cells. Tumour Biol 2014;35:8169-8178.

18 Chung SS, Adekoya D, Enenmoh I, Clarke O, Wang P, Sarkyssian M, Wu Y, Vadgama JV: Salinomycin abolished stat 3 and stat 1 interactions and reduced telomerase activity in colorectal cancer cells. Anticancer Res 2017;37:445-453.

19 Banerjee K, Resat H: Constitutive activation of stat3 in breast cancer cells: A review. Int J Cancer 2016;138:2570-2578. 


\section{Cellular Physiology Cell Physiol Biochem 2017;43:2353-2366

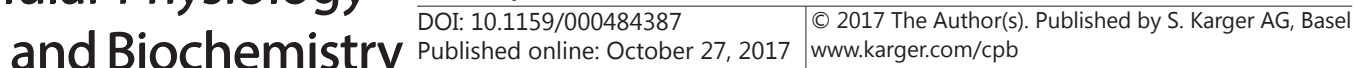 and Biochemistry $\frac{\text { Published online: October } 27,2017 \text { mas }}{\text { Xiao et al: Atractylenolide-1 Inhibits PDK1 Expression }}$}

20 Looyenga BD, Hutchings D, Cherni I, Kingsley C, Weiss GJ, Mackeigan JP: Stat3 is activated by jak2 independent of key oncogenic driver mutations in non-small cell lung carcinoma. PLoS One 2012;7:e30820.

-21 Beishline K, Azizkhan-Clifford J: Sp1 and the 'hallmarks of cancer'. FEBS J 2015;282:224-258.

22 Briggs MR, Kadonaga JT, Bell SP, Tjian R: Purification and biochemical characterization of the promoterspecific transcription factor, sp1. Science 1986;234:47-52.

-23 Imai K, Okamoto T, Ochiai K: Involvement of sp1 in butyric acid-induced hiv-1 gene expression. Cell Physiol Biochem 2015;37:853-865.

24 Vizcaino C, Mansilla S, Portugal J: Sp1 transcription factor: A long-standing target in cancer chemotherapy. Pharmacol Ther 2015;152:111-124.

-25 Deng R, Wu H, Ran H, Kong X, Hu L, Wang X, Su Q: Glucose-derived ages promote migration and invasion of colorectal cancer by up-regulating sp1 expression. Biochim Biophys Acta 2017;1861:1065-1074.

26 Zhao S, Wu J, Tang Q Zheng F, Yang L, Chen Y, Li L, Hann SS: Chinese herbal medicine xiaoji decoction inhibited growth of lung cancer cells through ampkalpha-mediated inhibition of sp1 and DNA methyltransferase 1. J Ethnopharmacol 2016;181:172-181.

27 Jeon YJ, Bang W, Choi YH, Shim JH, Chae JI: Beta-lapachone suppresses non-small cell lung cancer proliferation through the regulation of specificity protein 1. Biol Pharm Bull 2015;38:1302-1308.

28 Tang Q, Wu J, Zheng F, Hann SS, Chen Y: Emodin increases expression of insulin-like growth factor binding protein 1 through activation of mek/erk/ampkalpha and interaction of ppargamma and sp1 in lung cancer. Cell Physiol Biochem 2017;41:339-357.

29 Alcantara-Montiel JC, Staines-Boone T, Lopez-Herrera G, Espinosa-Rosales F, Espinosa-Padilla SE, Hernandez-Rivas R, Santos-Argumedo L: Functional characterization of two new stat3 mutations associated with hyper-ige syndrome in a mexican cohort. Clin Genet 2016;89:217-221.

-30 Sonawane PJ, Gupta V, Sasi BK, Kalyani A, Natarajan B, Khan AA, Sahu BS, Mahapatra NR: Transcriptional regulation of the novel monoamine oxidase renalase: Crucial roles of transcription factors sp1, stat3, and zbp89. Biochemistry 2014;53:6878-6892.

-31 Chang YJ, Chen KW, Chen CJ, Lin MH, Sun YJ, Lee JL, Chiu IM, Chen L: Sh2b1beta interacts with stat3 and enhances fibroblast growth factor 1-induced gene expression during neuronal differentiation. Mol Cell Biol 2014;34:1003-1019.

32 Gagliardi PA, di Blasio L, Primo L: Pdk1: A signaling hub for cell migration and tumor invasion. Biochim Biophys Acta 2015;1856:178-188.

33 Ye XW, Yu H, Jin YK, Jing XT, Xu M, Wan ZF, Zhang XY: Mir-138 inhibits proliferation by targeting 3-phosphoinositide-dependent protein kinase-1 in non-small cell lung cancer cells. Clin Respir J 2015;9:2733.

34 Feldman RI, Wu JM, Polokoff MA, Kochanny MJ, Dinter H, Zhu D, Biroc SL, Alicke B, Bryant J, Yuan S, Buckman BO, Lentz D, Ferrer M, Whitlow M, Adler M, Finster S, Chang Z, Arnaiz DO: Novel small molecule inhibitors of 3-phosphoinositide-dependent kinase-1. J Biol Chem 2005;280:19867-19874.

-35 Zheng N, Ding X, Sun A, Jahan R: Pdk1 activity regulates proliferation, invasion and growth of hemangiomas. Cell Physiol Biochem 2015;36:1903-1910.

-36 Raimondi C, Falasca M: Targeting pdk1 in cancer. Curr Med Chem 2011;18:2763-2769.

-37 Shimobaba S, Taga S, Akizuki R, Hichino A, Endo S, Matsunaga T, Watanabe R, Yamaguchi M, Yamazaki Y, Sugatani J, Ikari A: Claudin-18 inhibits cell proliferation and motility mediated by inhibition of phosphorylation of pdk1 and akt in human lung adenocarcinoma a549 cells. Biochim Biophys Acta 2016;1863:1170-1178.

-38 Akizuki R, Shimobaba S, Matsunaga T, Endo S, Ikari A: Claudin-5, -7, and -18 suppress proliferation mediated by inhibition of phosphorylation of akt in human lung squamous cell carcinoma. Biochim Biophys Acta 2017;1864:293-302.

39 Pawlus MR, Wang L, Hu CJ: Stat3 and hif1alpha cooperatively activate hif1 target genes in mda-mb-231 and rcc4 cells. Oncogene 2014;33:1670-1679.

40 Yang B, Singh S, Bressani R, Kanmogne GD: Cross-talk between stat1 and pi3k/akt signaling in hiv-1induced blood-brain barrier dysfunction: Role of ccr5 and implications for viral neuropathogenesis. J Neurosci Res 2010;88:3090-3101.

41 Lopez-Bergami P, Kim H, Dewing A, Goydos J, Aaronson S, Ronai Z: C-jun regulates phosphoinositidedependent kinase 1 transcription: Implication for akt and protein kinase c activities and melanoma tumorigenesis. J Biol Chem 2010;285:903-913. 


\section{Cellular Physiology Cell Physiol Biochem 2017;43:2353-2366 \begin{tabular}{l|l|l}
\hline and Biochemistry 10.1159/000484387 & $\begin{array}{l}\text { C } 2017 \text { The Author(s). Published by S. Karger AG, Basel } \\
\text { www.karger.com/cpb }\end{array}$ \\
\hline
\end{tabular} \\ Xiao et al.: Atractylenolide-1 Inhibits PDK1 Expression}

42 Zheng F, Tang Q Wu J, Zhao S, Liang Z, Li L, Wu W, Hann S: P38alpha mapk-mediated induction and interaction of foxo3a and p53 contribute to the inhibited-growth and induced-apoptosis of human lung adenocarcinoma cells by berberine. J Exp Clin Cancer Res 2014;33:36.

43 Zhao S, Wu J, Zheng F, Tang Q, Yang L, Li L, Wu W, Hann SS: Beta-elemene inhibited expression of DNA methyltransferase 1 through activation of erk1/2 and ampkalpha signalling pathways in human lung cancer cells: The role of sp1. J Cell Mol Med 2015;19:630-641.

44 Hann SS, Chen J, Wang Z, Wu J, Zheng F, Zhao S: Targeting ep4 by curcumin through cross talks of ampdependent kinase alpha and p38 mitogen-activated protein kinase signaling: The role of pgc-1alpha and sp1. Cell Signal 2013;25:2566-2574.

45 Yu R, Yu BX, Chen JF, Lv XY, Yan ZJ, Cheng Y, Ma Q: Anti-tumor effects of atractylenolide i on bladder cancer cells. J Exp Clin Cancer Res 2016;35:40.

46 Deschenes-Simard X, Kottakis F, Meloche S, Ferbeyre G: Erks in cancer: Friends or foes? Cancer Res 2014;74:412-419.

47 Qi QR, Yang ZM: Regulation and function of signal transducer and activator of transcription 3. World J Biol Chem 2014;5:231-239.

48 Forootan FS, Forootan SS, Gou X, Yang J, Liu B, Chen D, Al Fayi MS, Al-Jameel W, Rudland PS, Hussain SA, Ke Y: Fatty acid activated ppargamma promotes tumorigenicity of prostate cancer cells by up regulating vegf via ppar responsive elements of the promoter. Oncotarget 2016;7:9322-9339.

-49 Huang JM, Zhang GN, Shi Y, Zha X, Zhu Y, Wang MM, Lin Q, Wang W, Lu HY, Ma SQ Cheng J, Deng BF: Atractylenolide-i sensitizes human ovarian cancer cells to paclitaxel by blocking activation of tlr4/myd88dependent pathway. Sci Rep 2014;4:3840.

50 Wu J, Ding Y, Chen CH, Zhou Z, Ding C, Chen H, Zhou J, Chen C: A new oridonin analog suppresses triple-negative breast cancer cells and tumor growth via the induction of death receptor 5. Cancer Lett 2016;380:393-402.

51 Meng G, Chai K, Li X, Zhu Y, Huang W: Luteolin exerts pro-apoptotic effect and anti-migration effects on a549 lung adenocarcinoma cells through the activation of mek/erk signaling pathway. Chem Biol Interact 2016;257:26-34.

-52 Slawinska-Brych A, Zdzisinska B, Dmoszynska-Graniczka M, Jeleniewicz W, Kurzepa J, Gagos M, Stepulak A: Xanthohumol inhibits the extracellular signal regulated kinase (erk) signalling pathway and suppresses cell growth of lung adenocarcinoma cells. Toxicology 2016;357-358:65-73.

53 Cao Y, Liang H, Zhang F, Luan Z, Zhao S, Wang XA, Liu S, Bao R, Shu Y, Ma Q, Zhu J, Liu Y: Prohibitin overexpression predicts poor prognosis and promotes cell proliferation and invasion through erk pathway activation in gallbladder cancer. J Exp Clin Cancer Res 2016;35:68.

54 Chen HX, Xu XX, Tan BZ, Zhang Z, Zhou XD: Microrna-29b inhibits angiogenesis by targeting vegfa through the mapk/erk and pi3k/akt signaling pathways in endometrial carcinoma. Cell Physiol Biochem 2017;41:933-946.

55 Wei Z, Jiang X, Qiao H, Zhai B, Zhang L, Zhang Q, Wu Y, Jiang H, Sun X: Stat3 interacts with skp2/p27/p21 pathway to regulate the motility and invasion of gastric cancer cells. Cell Signal 2013;25:931-938.

56 Huang C, Xie K: Crosstalk of sp1 and stat3 signaling in pancreatic cancer pathogenesis. Cytokine Growth Factor Rev 2012;23:25-35.

57 Markovic J, Uskokovic A, Grdovic N, Dinic S, Mihailovic M, Jovanovic JA, Poznanovic G, Vidakovic M: Identification of transcription factors involved in the transcriptional regulation of the cxcl12 gene in rat pancreatic insulinoma rin-5f cell line. Biochem Cell Biol 2015;93:54-62.

58 Qin L, Tian Y, Yu Z, Shi D, Wang J, Zhang C, Peng R, Chen X, Liu C, Chen Y, Huang W, Deng W: Targeting pdk1 with dichloroacetophenone to inhibit acute myeloid leukemia (aml) cell growth. Oncotarget 2016;7:13951407.

59 Du J, Yang M, Chen S, Li D, Chang Z, Dong Z: Pdk1 promotes tumor growth and metastasis in a spontaneous breast cancer model. Oncogene 2016;35:3314-3323.

60 Daniele S, Sestito S, Pietrobono D, Giacomelli C, Chiellini G, Di Maio D, Marinelli L, Novellino E, Martini C, Rapposelli S: Dual inhibition of pdk1 and aurora kinase a: An effective strategy to induce differentiation and apoptosis of human glioblastoma multiforme stem cells. ACS Chem Neurosci 2017;8:100-114. 